\title{
Tool Stresses in Soft and Hard Finish Turning with Low Content CBN Tool by Finite Elements Analysis
}

\author{
B. YAlÇIN ${ }^{a, *}$, N. YILMAZ ${ }^{a}$ AND A. KURT ${ }^{b}$ \\ ${ }^{a}$ Süleyman Demirel University, Department of Mechanical and Manufacturing Engineering, 32260 Isparta, Turkey \\ ${ }^{b}$ Gazi University, Department of Manufacturing Engineering, Teknikokullar, 06500 Ankara, Turkey \\ This study is performed to understand the effect of workpiece hardness and cutting parameters on cutting \\ tool stresses in finish turning of soft (22 HRc) and hardened (52 HRc) H13 steel using low content CBN cutting \\ tool by finite element analysis. For this aim, a series of precision dry turning tests were conducted with different \\ cutting parameters $(V: 150,250,350 \mathrm{~m} / \mathrm{min} ; f: 0.05,0.2,0.35 \mathrm{~mm} / \mathrm{rev} ., a: 0.2,0.5,0.8 \mathrm{~mm})$ and then the cutting \\ forces $F_{\mathrm{c}}, F_{\mathrm{f}}, F_{\mathrm{p}}$ were recorded. Finite element analysis shows that cutting stresses decrease with increasing depth \\ of cut due to the increase of the tool-chip contact length/area. The low depth of cut and high feed rate lead to \\ small chip contact region on the rake face and as a result increase the compression stresses. Finite element analysis \\ of tool stress results gives information for selection of the optimum cutting parameters and shows that the largest \\ compression stresses focused on the tool-chip contact region may cause the crater wear. The large tensile stress \\ occurring under nose radius of the main cutting edge can lead to the flank and notch wear modes.
}

DOI: 10.12693/APhysPolA.134.48

PACS/topics: finite elements analysis, tool stresses, turning, tool-chip contact region, flank wear, notch wear

\section{Introduction}

The present trend in machining industry is to produce parts of higher quality in a shorter time and at a lower cost. This trend is realized via the precision hard-turning of materials with hardness higher than 45 HRC. Hard turning has recently become a very important precision machining procedure in the manufacturing of circular parts with high values of surface hardness such as dies and moulds, bearings, gears, pinions, shafts, cams, valves and a variety of automotive transmission parts as well as some other products like helicopter shafts in aerospace industry [1]. It is known that precision hard turning has many advantages compared with grinding, such as short cycle time, process flexibility, reasonable surface finish, higher material removal rate and lesser environment problems without the use of cutting fluid [2-4]. On the other hand, Lazoğlu et al. [5] have shown that early tool wear, tool breakage, chipping, tool stresses, cutting temperatures, residual stresses, white layer phenomena, machined surface quality and surface integrity are very important issues in hard machining industrial applications.

Some literature surveys have reported that hard turning applications can be performed using PCBN (common $\mathrm{CBN}$ ) and mixed ceramics cutting tool materials which eliminate the costs and difficulties associated with coolants and have pointed out on their high hardness, high abrasive wear resistance and chemical stability at high temperatures $[1,6,7]$.

CBN tools are some of the hardest known after diamond tools and have a higher hardness than ceramic

*corresponding author; e-mail: bekiryalcin@sdu.edu.tr tools at both low and high temperatures. Therefore, CBN tools were widely used in milling of difficult-tomachine materials such as hardened steel, die steel and super alloys [8-10].

The main characteristics of $\mathrm{CBN}$ are its grain size, its percentage of $\mathrm{CBN}$ and its binder type. In general, CBN tools are made of varied CBN contents with some additives. There are two categories of CBN tools. One has about 0.9 volume fraction of $\mathrm{CBN}$ grains with metallic binders (e.g., cobalt), referred to as high $\mathrm{CBN}$ content tools. The other has about 0.5 to 0.7 volume fraction of CBN grains with ceramic binders (e.g., titanium nitride TiN, titanium carbide $\mathrm{TiC}$ ), referred to as low CBN content tools [11]. It is known that, when comparing the low content $\mathrm{CBN}$ and high content CBN tools, low content CBN tools are generally suited in machining of hard materials [12].

Various studies have been conducted to determine the performance of CBN tools in machining of hard materials focusing mostly on the experimental evaluation of such process parameters as chip morphology, chip formation, machinability and tool wear [12-15].

Chou, et al. [12] experimentally investigated the performance and wear behaviour of different CBN tools in finish turning of hardened AISI 52100 steel. They reported that low content CBN tool provides the best performance in hard turning in terms of tool life and surface finish.

Qian, et al. [13] compared cutting forces, temperature, and residual stress in hard turning 52100 with CBN, TiAlN-coated carbide, and ceramics turning inserts. They have concluded that forces increase with increasing feed rate, tool edge radius, negative rake angle, and workpiece hardness.

Aouici, et al. [14] investigated the effects of cutting speed, feed rate, workpiece hardness and depth of cut on 
surface roughness and cutting force components in the hard turning of AISI H11 steel with CBN. They reported that the best surface roughness was achieved at the lower feed rate and the highest cutting speed.

Finaly, Farhat [16] studied wear mechanism of CBN cutting tool during high-speed machining of mold steel. He has clarified that a significant improvement in tool wear resistance of $\mathrm{CBN}$ was achieved in comparison to WC tools during high speed cutting of P20 mold steel.

In recent years, in order to understand the issues of metal cutting engineering, the numerical models, especially related to FEM, have been drawing the attention of the researchers due to development of computer technology and complex codes. Eulerian formulation was used for modelling of the orthogonal metal cutting in a number of the FEM models in the literature. However, because of the ability to simulate the formation of the chip from the incipient stages to steady-state, the Lagrangian formulation has also become widespread in metal cutting.

To improve the accuracy and the efficiency of the FEM in metal cutting, such techniques as element separation criterion [17-22] were investigated. There are also a lot of papers in the literature [23-27] about the variation of the cutting tool stresses with respect to the variations of the cutting parameters.

In the literature [21-30], the FEM is most frequently used to predict the tool stresses, temperatures and characteristics of the metal cutting process and to reduce experimental costs. For instance, Yan, et al. [28] stated that because the flow stress models used in computer simulation of machining processes are functions of the effective strain, the effective strain rate and the temperature, these models do not describe adequately the behavior of materials in hard machining. The obtained results show that optimization of process parameters and improvement of the design of cutting inserts are helpful.

The phenomenological models for material flow stress and fracture typically used in the FE simulations of hard machining do not adequately represent the constitutive behavior of workpiece at hardness levels ranging from 50 to $62 \mathrm{HRC}$ by Umbrella, et al. [29]. Authors of [29] describe the development of hardness-based flow stress and fracture models for AISI H13 machining tool steels. Their results predicted by FEA have been validated by comparing them with experimental results from literature. The results were found to be in agreement with each other.

Özel [30] carried out the FE modelling investigations on 3D turning with uniform and variable edge PCBN inserts. According to FEM simulations and experiments conducted by Özel, variable micro-geometry insert edge design reduces significantly the heat generation and stress concentration along the cutting edge of the tool.

In addition, Karpat and Özel [31] studied the analytical and thermal modeling of high-speed machining with chamfered tools. They reported that combined slip-line field analysis and analytical thermal modeling approach can be used in studying the influence of dead metal zone on the mechanics of high-speed cutting. Their modelling results show that the dead metal zone primarily affects the temperature distribution around the tip of the tool and eases the material flow due to thermal softening with increased temperatures.

The cutting stress affecting the cutting tool during machining in metal cutting is one of very important parameters for selecting the economical cutting conditions and for obtaining securely high quality workpieces.

In the present paper, the cutting tool stresses in finish turning of soft and hardened AISI H13 steel with low content CBN tool were investigated using FE analysis. To understand the tool stresses, firstly, the precision turning tests were conducted, and the cutting forces were measured during a series of turning tests. Secondly, the finite element models were actually created to analyze the tool stresses using the measured cutting forces.

\section{Materials and equipment}

The initial aim of cutting experiments is to determine the finish turning characteristic of the soft (average $22 \mathrm{HRC}$ ) and hardened (average $52 \mathrm{HRC}$ ) AISI H13 steel with the following chemical composition: $0.42 \% \mathrm{C}$; $1.2 \% \mathrm{Si} ; 0.5 \% \mathrm{Mn} ; 0.025 \% \mathrm{P} ; 0.005 \% \mathrm{~S} ; 5.5 \% \mathrm{Cr}$; $1.5 \% \mathrm{Mo} ; 1.15 \% \mathrm{~V}$. This was performed by dry finish turning of soft and hardened AISI H13 steel with three different cutting speeds $(V: 150,250,350 \mathrm{~m} / \mathrm{min})$, feed rates $(f: 0.05,0.2,0.35 \mathrm{~mm} / \mathrm{rev})$ and depths of cut $(a$ : $0.2,0.5,0.8 \mathrm{~mm}$ ) using low content $\mathrm{CBN}$ tool. The best finish turning parameters selected from tool manufacturer catalogs are shown in Table I.

TABLE I

Cutting parameters used in the experiments.

\begin{tabular}{c|c|c}
\hline \hline$V[\mathrm{~m} / \mathrm{min}]$ & $a[\mathrm{~mm}]$ & $f[\mathrm{~mm} / \mathrm{rev}]$ \\
\hline 150 & 0.2 & 0.2 \\
350 & 0.2 & 0.2 \\
150 & 0.5 & 0.35 \\
350 & 0.5 & 0.35 \\
150 & 0.8 & 0.05 \\
350 & 0.8 & 0.05 \\
250 & 0.2 & 0.35 \\
250 & 0.5 & 0.05 \\
250 & 0.8 & 0.2
\end{tabular}

Values of cutting parameter were determined using Taguchi method. Afterwards, hard turning test was performed during the straight turning of the round bar with $100 \mathrm{~mm}$ diameter and $220 \mathrm{~mm}$ length using a CNC lathe of type ALEX ANL-75 with $15 \mathrm{~kW}$ spindle power.

During turning tests, the cutting forces (the primary cutting force $F_{\mathrm{c}}$, the feed force $F_{\mathrm{f}}$ and the passive/radial force $F_{\mathrm{p}}$ ) were recorded. The Kistler $9257 \mathrm{~B}$ force dynamometer was used to measure the cutting forces. The dynamometer was connected to Kistler charge amplifier 5070A11100.

The PVD TiN coated low content CBN 7015 tool from Sandvik Company was used in the tests. The ISO 
designation of low content (50\%) CBN 7015 insert is CNGA120408S01018A 7015. This cutting tool has wiper edge with honing radius of $0.05 \mathrm{~mm}$, with face land length of $0.1 \mathrm{~mm}$, face land angle of $18^{\circ}$, and nose radius of $0.8 \mathrm{~mm}$. The ISO designation of the tool holder is DCLNL2525M12.

Combination of the insert and the tool holder resulted in negative rake angle $\gamma=-6^{\circ}$, clearance angle $\alpha=-6^{\circ}$, and cutting edge angle $\chi=95^{\circ}$.

For the FEA, ANSYS program package was used to analyze the cutting tool stresses after some preparations. These preparations include: the three-dimensional solid modelling of the cutting tools, determining the material properties of the cutting tool and the tool holder, determining the type and the size of the finite elements, meshing of the models, identifying the boundary conditions and load cases and selection of the solution method.

The cutting tool and tool holder were then dimensioned using measurement device according to CNGA120408S01018A7015 and DCLNL2525M12 ISO standards.

The geometric features of the cutting tools such as rake angle, inclination angle, clearance angles, nose radius, honing radius, chamfer angle, etc. were modeled with the SolidWorks design program and then the created model was imported from SolidWorks to ANSYS program. During the modelling of cutting tools, the toolchip contact region was also taken into account according to Zorev's [32] stress distributions on rake face in the literature $[25,26,33]$. The tool-chip contact length was expressed as the sum of the lengths of sticking and sliding regions ( $h_{1}$ and $h_{2}$, respectively), which is calculated as follows [34]:

$$
\begin{aligned}
& \varnothing=\arctan \left[\frac{\cos \gamma}{\lambda-\sin \gamma}\right], \\
& \frac{L_{\mathrm{c}}}{a}=2 a, \\
& L_{\mathrm{c}}=h_{1}+h_{2}=2 \lambda a .
\end{aligned}
$$

In Eqs. [1-3], $L_{\mathrm{c}}, a, \lambda, \varphi$ and $\gamma$ are the length of tool-chip contact, the depth of cut (the undeformed chip thickness), the chip built factor $\left(\lambda=a_{1} / a\right)$, where $a_{1}$ is the chip thickness and $a$ is depth of cut, the shear angle and the rake angle, respectively. Toropov and Ko [34] have shown that slip-line model (Eq. (3)) is correct, at least in the chip body, for all used materials and cutting conditions.

According to Eq. (3), tool-chip contact regions with $L_{\mathrm{c}}=0.3368,0.8421$ and $1.3474 \mathrm{~mm}$ have occurred on the rake face of cutting tool for depths of cut $a=0.2$, $0.5,0.8 \mathrm{~mm}$, respectively. Solid models for the cutting tool and the tool holder are shown in Fig. 1. Material properties such as modulus of elasticity E, Poisson's ratio $\nu$ and density $\rho$ for the models of cutting tool and tool holder are given in Table II. The values of these parameters for the cutting tool (CBN insert) and the tool holder were taken from [31, 35-37], respectively.

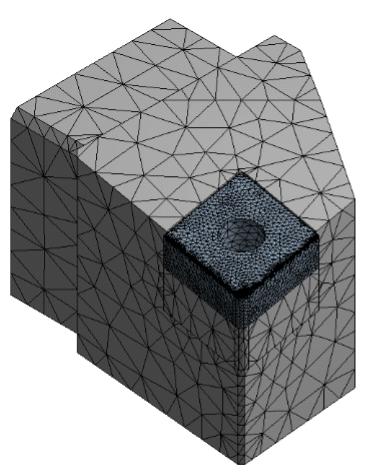

(a)

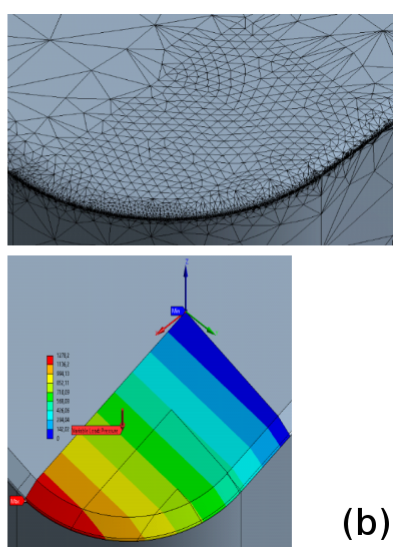

(b)
Fig. 1. Mesh of finite elements for the cutting tool (a). The tool-chip contact region and variable loading (b).

TABLE II

Material models for the DCLNL 2525M 12-2 tool holder and CNGA120408S01018A7015CBN insert.

\begin{tabular}{l|c|c|c}
\hline \hline & $E[\mathrm{GPa}]$ & $\nu$ & $\rho\left[\mathrm{kg} / \mathrm{mm}^{3}\right]$ \\
\hline Tool holder & 210.7 & 0.28 & 0.0000078 \\
Insert & 587 & 0.13 & 0.00000428
\end{tabular}

SOLID187 element type was used to describe the cutting tools in the model by taking into account the literature [26, 37]. The interaction in the contact regions is achieved by the quadratic triangle elements Conta174 and Targe 170 .

The mesh density was selected to be dense in the tool-chip contact regions on rake face of the insert and sparse in other parts of the cutting tool (Fig. 1a). The total of 38880 nodes and 24131 elements were used in the analysis.

The behavior of contact between the contact surfaces is bonded symmetrically in all directions. Therefore, in order to clamp the insert to the tool holder, no additional clamping force is necessary.

According to Zorev's theory [32] of stress distribution on the rake face of the cutting tool, the cutting forces $F_{\mathrm{c}}$, $F_{\mathrm{f}}$ and $F_{\mathrm{p}}$ acting on the cutting tool are applied to the tool-chip contact region according to the following procedure. The cutting forces $F_{\mathrm{f}}$ and $F_{\mathrm{p}}$ are directly applied to the related tool-chip contact region in the direction of the feed and the radial motions of the cutting tool, respectively. However, the cutting force $F_{\mathrm{c}}$ was applied to tool-chip contact region as triangular variable loading (pressure). In this case loading value was 0 at the end of the tool-chip contact region (the origin of coordinate system is shown in Fig. 1b, the location assumed that the chip is curled and moved away from the rake face), whereas loading was highest at the location of first contact between the chip and the cutting tool. These loads were applied to the tool-chip contact region and then were actually transferred to SURF154, used to define the loading region and the corresponding nodes.

As boundary condition for constraint, the number of 
degrees of freedom of the nodes in the area mounted into the tool holder was set to zero in all directions. The Following assumptions were made to reduce the calculation time in the analysis: the inserts are new, the weights of the cutting tools, the vibrations and the temperatures were neglected. The method of static analysis was used. It was also assumed that the displacements caused by the cutting forces are very small with respect to the solid model geometry and are proportional to the applied load and that the cutting tool returns to the original position when the applied load is removed.

After these preparations, the program solved the finite element problem as non-linear due to the contact pairs between the surfaces of the tool holder and the cutting tool. In solving, large deflection was not used and the convergence criterion can be continuously controlled via the relation between forces and displacements in each iterative solution step. Eventually, the total deformation $\Delta$, maximum principal stress (tension) $\sigma_{1}$, minimum principal stress (compression) $\sigma_{3}$ and equivalent stress $\sigma_{\mathrm{VM}}$ were investigated for various cutting parameters, in terms of the possible wear areas on the rake face of cutting tool.

\section{Results and discussion}

During finish turning of soft and hardened AISI H13 steel, the $F_{\mathrm{c}}, F_{\mathrm{p}}$, and $F_{f}$ forces were measured for different cutting parameters. The measured cutting forces are presented in Fig. 2. Figure 2 shows the effect of the hardness of workpiece material and of cutting parameters on cutting forces. The general result is that a decreasing trend is observed in $F_{\mathrm{c}}$ forces for both soft and hard finish turning tests with increasing the cutting speed, with decreasing the feed rate and the depth of cut.

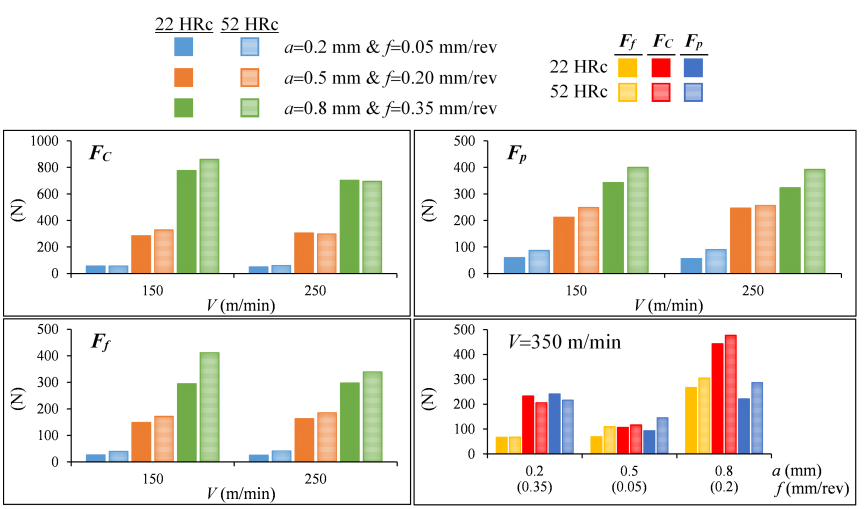

Fig. 2. Changes of the cutting forces $F_{\mathrm{c}}, F_{\mathrm{p}}, F_{\mathrm{f}}$ with the variation cutting parameters.

Aouici et al. [14] experimentally determined that in hard machining, the cutting forces decrease with increasing cutting velocity and decreasing feed rate. In addition, $F_{\mathrm{c}}$ forces increase with increasing hardness of the workpiece. Bouacha et al. [38] reported that cutting forces increased with increasing workpiece hardness. It is known that a passive force has the strongest effect on the surface roughness in precision turning.
For instance, in finish turning with cutting speed of $250 \mathrm{~m} / \mathrm{min}$, feed rate of $0.35 \mathrm{~mm} / \mathrm{rev}$ and depth of cut of $0.8 \mathrm{~mm}$, the $F_{\mathrm{p}}$ force increases by $21.3 \%$ with increasing the AISI H13 steel hardness from 22 HRc to 52 HRc. The main result is that the feed rate has the most effect on the passive forces and a stronger increasing trend was observed with increasing the feed rate and the workpiece hardness. A similar trend was reported in literature [39, 40].

Finally, the feed forces are also presented in Fig. 2. It can be seen that when comparing the cutting forces, the values of the feed force were found to be the smallest in finishing operations. When comparing the effect of workpiece hardness on cutting forces, the highest increasing trend of $39.7 \%$ was observed in feed forces. In addition, a notable decreasing trend in feed forces was observed at increasing the cutting speed and decreasing the depth of cut and the feed rate.

The tool stresses in metal cutting generally depend on cutting parameters. In order to estimate stresses on low content CBN during the precision turning of soft and hard H13 steel the FAE was carried out, considering the measured cutting forces and tool-chip contact length theory of Toropov and Zorev [32, 34].

Tensile $\sigma_{1}$ and compression stresses $\sigma_{3}$ and von-Mises stresses $\sigma_{\mathrm{VM}}$ together with total deformation were obtained for finish turning of soft and hard H13 steel.

Figure 3a shows the effect of workpiece hardness and finish turning parameters on total deformation. The highest tool total deformation of $0.0061765 \mathrm{~mm}$ occurred in soft material finishing with $V=350 \mathrm{~m} / \mathrm{min}, a=$ $0.2 \mathrm{~mm}$ and $f=0.35 \mathrm{~mm} / \mathrm{rev}$. In hard finish turning with the same cutting parameters, the total deformation of the tool was found to be $0.0055734 \mathrm{~mm}$. When comparing the highest tool total deformations for soft and hard material finish turning, the total deformation in turning of soft $\mathrm{H} 13$ steel is $10.8 \%$ higher than that of hard H13 turning. The smallest total deformation in turning of soft and hard workpiece materials was $0.0010695 \mathrm{~mm}$ and $0.0018405 \mathrm{~mm}$, respectively, at $V=350 \mathrm{~m} / \mathrm{min}$, $a=0.5 \mathrm{~mm}$ and $f=0.05 \mathrm{~mm} / \mathrm{rev}$.

While the total tool deformation in soft and hard material finishing was $0.0040917 \mathrm{~mm}$ and $0.0045669 \mathrm{~mm}$, respectively, at $V=150 \mathrm{~m} / \mathrm{min}, a=0.8 \mathrm{~mm}$ and $f=$ $0.35 \mathrm{~mm} / \mathrm{rev}$, lower total deformations in soft and hard material finishing of $0.0036771 \mathrm{~mm}$ and $0.0034850 \mathrm{~mm}$, respectively, were obtained at $V=250 \mathrm{~m} / \mathrm{min}, a=$ $0.8 \mathrm{~mm}$ and $f=0.35 \mathrm{~mm} / \mathrm{rev}$.

The important result is that, the total deformation in finish turning of hard $\mathrm{H} 13$ steel with high cutting velocity $(250 \mathrm{~m} / \mathrm{min}$ and $350 \mathrm{~m} / \mathrm{min})$ is lower than that of finish turning of soft $\mathrm{H} 13$ steel with cutting velocity of $150 \mathrm{~m} / \mathrm{min}$. The decreasing trend in tool total deformation during turning the hard workpiece materials was found to be $11.6 \%$ according to tool total deformation of soft material finishing with increasing the cutting speed from $150 \mathrm{~m} / \mathrm{min}$ to $250 \mathrm{~m} / \mathrm{min}$ when using $a=0.8 \mathrm{~mm}$ and $f=0.35 \mathrm{~mm} / \mathrm{rev}$. Hence, the higher 


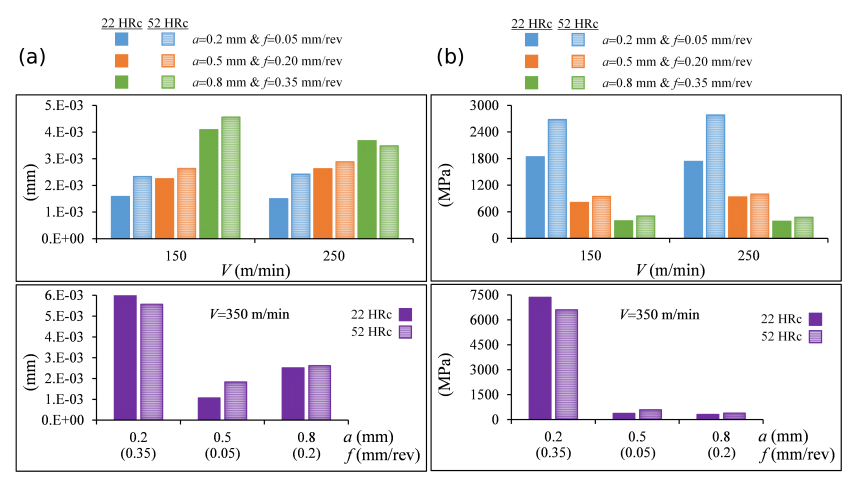

Fig. 3. Variation of the total deformation (a), and $\sigma_{1}$ stress (b) for tested cutting parameters.

is cutting speed for the same depth of cut (especially $a=0.8 \mathrm{~mm})$ and feed rate $(f=0.35 \mathrm{~mm} / \mathrm{rev})$, the smaller is tool deformation.

The total tool deformation in hard finishing is lower than that of soft finishing at $V=350 \mathrm{~m} / \mathrm{min}, a=0.2 \mathrm{~mm}$ and $f=0.35 \mathrm{~mm} / \mathrm{rev}$. The lowest tool total deformation was obtained at finish turning with cutting velocity of $350 \mathrm{~m} / \mathrm{min}$, depth of cut of $0.5 \mathrm{~mm}$ and the feed rate of $0.05 \mathrm{~mm} / \mathrm{rev}$. The general result concerning the total deformation of the tool is that total deformation increases with increasing feed rate and depth of cut (Fig. 3a).

The tensile stress $\sigma_{1}$ for various cutting parameters and workpiece hardness is given in Fig. 3b. The highest tensile stress in both soft and hard finish turning was, respectively, $7362.5 \mathrm{MPa}$ and $6612.5 \mathrm{MPa}$ at the cutting speed of $350 \mathrm{~m} / \mathrm{min}$, depth of cut of $0.2 \mathrm{~mm}$ and feed rate of $0.35 \mathrm{~mm} / \mathrm{rev}$. Tensile stress in hard turning is $11.3 \%$ lower than that of soft finish turning at the cutting speed of $350 \mathrm{~m} / \mathrm{min}$, depth of cut of $0.2 \mathrm{~mm}$ and feed rate of $0.35 \mathrm{~mm} / \mathrm{rev}$.

The small depth of cut and the high feed rate lead to increase in tensile stress in the cutting tool at $V=350 \mathrm{~m} / \mathrm{min}$ while turning the soft workpiece material. However, decreasing the feed rate from $f=0.35 \mathrm{~mm}$ to $0.05 \mathrm{~mm} / \mathrm{rev}$ and decreasing the depth of cut from $0.2 \mathrm{~mm}$ to $0.05 \mathrm{~mm}$ decreases the tensile stresses at cutting velocity of $350 \mathrm{~m} / \mathrm{min}$.

For instance, in hard and soft turning, the tensile stresses were found to be 592.26 MPa and 368.41 MPa, respectively, at $V=350 \mathrm{~m} / \mathrm{min}, a=0.5 \mathrm{~mm}$ and $f=0.05 \mathrm{~mm} / \mathrm{rev}$. This can be interpreted as follows, increase of the depth of cut from $0.2 \mathrm{~mm}$ to $0.5-0.8 \mathrm{~mm}$ provides larger tool-chip contact length/region. The decrease of the feed rate from $0.35 \mathrm{~mm} / \mathrm{rev}$ to $0.05 \mathrm{~mm} / \mathrm{rev}$ makes the chip flow on the tool tip easier, thus a smaller tensile stress occurs due to the larger tool-chip contact length in soft and hard finish turning at cutting velocity of $350 \mathrm{~m} / \mathrm{min}$.

In finishing of soft workpiece material, increase of the feed rate leads to increase in tensile stress, focusing on the tool cutting edge. The highest tensile stress occurs due to the decrease of the tool chip contact length at the lowest depth of cut of $0.2 \mathrm{~mm}$ in hard finish turning with the same cutting parameters. Therefore, it is an important result that in order to decrease the tensile stress firstly the feed rate must be decreased and secondly the depth of cut can be increased up to nose radius, and finally cutting velocity can also be increased to the allowable value.

According to Fig. 3b, tensile stresses decrease with the increasing depth of cut, because increasing the depth of cut from $0.2 \mathrm{~mm}$ to $0.8 \mathrm{~mm}$ provides the large toolchip contact length. It is know that tool stress decreases with increasing contact area, depending on depth of cut and feed rate. For example, while the tensile stresses in tool during finish turning of soft and hard H13 steel were respectively 1842.4 MPa and 2683.3 MPa at $V=150 \mathrm{~m} / \mathrm{min}, a=0.2 \mathrm{~mm}$ and $f=0.05 \mathrm{~mm} / \mathrm{rev}$, the tensile stresses were respectively $1783.8 \mathrm{MPa}$ and $2784.2 \mathrm{MPa}$ at $V=250 \mathrm{~m} / \mathrm{min}, a=0.2 \mathrm{~mm}$ and $f=0.05 \mathrm{~mm} / \mathrm{rev}$.

Thence, in the same cutting conditions, the tensile stress at hard turning was found to be increased by $45 \%$ with changing the workpiece hardness from $22 \mathrm{HRC}$ to $52 \mathrm{HRc}$ at $V=150 \mathrm{~m} / \mathrm{min}, a=0.2 \mathrm{~mm}$ and $f=0.05 \mathrm{~mm} / \mathrm{rev}$. In soft material finishing, a decreasing trend of $3.3 \%$ in tensile stress was observed with increasing the cutting speed from $150 \mathrm{~m} / \mathrm{min}$ to $250 \mathrm{~m} / \mathrm{min}$. On the other hand, a $3.7 \%$ increase in $\sigma_{1}$ was obtained with increasing the cutting speed from $150 \mathrm{~m} / \mathrm{min}$ to $250 \mathrm{~m} / \mathrm{min}$ in hard turning. A $98 \%$ decrease in $\sigma_{1}$ was also observed with increasing the depth of cut from $0.5 \mathrm{~mm}$ to $0.8 \mathrm{~mm}$ at $V=250 \mathrm{~m} / \mathrm{min}$ and $f=0.2 \mathrm{~mm} / \mathrm{rev}$ in hard turning. With the increase of allowable values of the depth of cut, the tensile stresses decreased. It can be seen in Fig. $3 \mathrm{~b}$ that while the lowest tensile stress in soft turning was $309.36 \mathrm{MPa}$ at $V=350 \mathrm{~m} / \mathrm{min}, f=0.2 \mathrm{~mm} / \mathrm{rev}$ and $a=0.8 \mathrm{~mm}$, the lowest tensile stress was $390.13 \mathrm{MPa}$ in hard finish turning at $V=350 \mathrm{~m} / \mathrm{min}, f=0.2 \mathrm{~mm} / \mathrm{rev}$ and $a=0.8 \mathrm{~mm}$.

When evaluating Fig. 3b, the tensile stress in soft turning is higher than that of hard turning at $V=$ $350 \mathrm{~m} / \mathrm{min}, f=0.35 \mathrm{~mm} / \mathrm{rev}$ and $a=0.8 \mathrm{~mm}$. It means that tensile stresses occurring near the nose radius and under the cutting edge (Fig. 4) in soft finish turning are higher than those of hard finish turning. Therefore, in order to decrease the tensile stresses in finishing the soft H13 steel, the cutting speed must be increased to easy the chip flow on tool tip. In addition, the cutting speed together with allowable depth of cut must be increased and the allowable minimum feed rate must be selected to decrease the tool tensile stress and to increase the product surface quality while finish turning of hard materials.

The behaviour of compression stress present on the tool rake face is similar to that of tensile stress present near the nose radius and under the cutting edge. It can be seen in Fig. 5a that the compression stresses $\sigma_{3}$ decrease with the increase in depth of cut, providing a large tool-chip contact length/area. The highest effect of workpiece hardness on $\sigma_{3}$ was observed at low cutting speed of $150 \mathrm{~m} / \mathrm{min}$, depth of cut of $0.2 \mathrm{~mm}$ and feed rate of $0.05 \mathrm{~mm} / \mathrm{rev}$. 
(a)
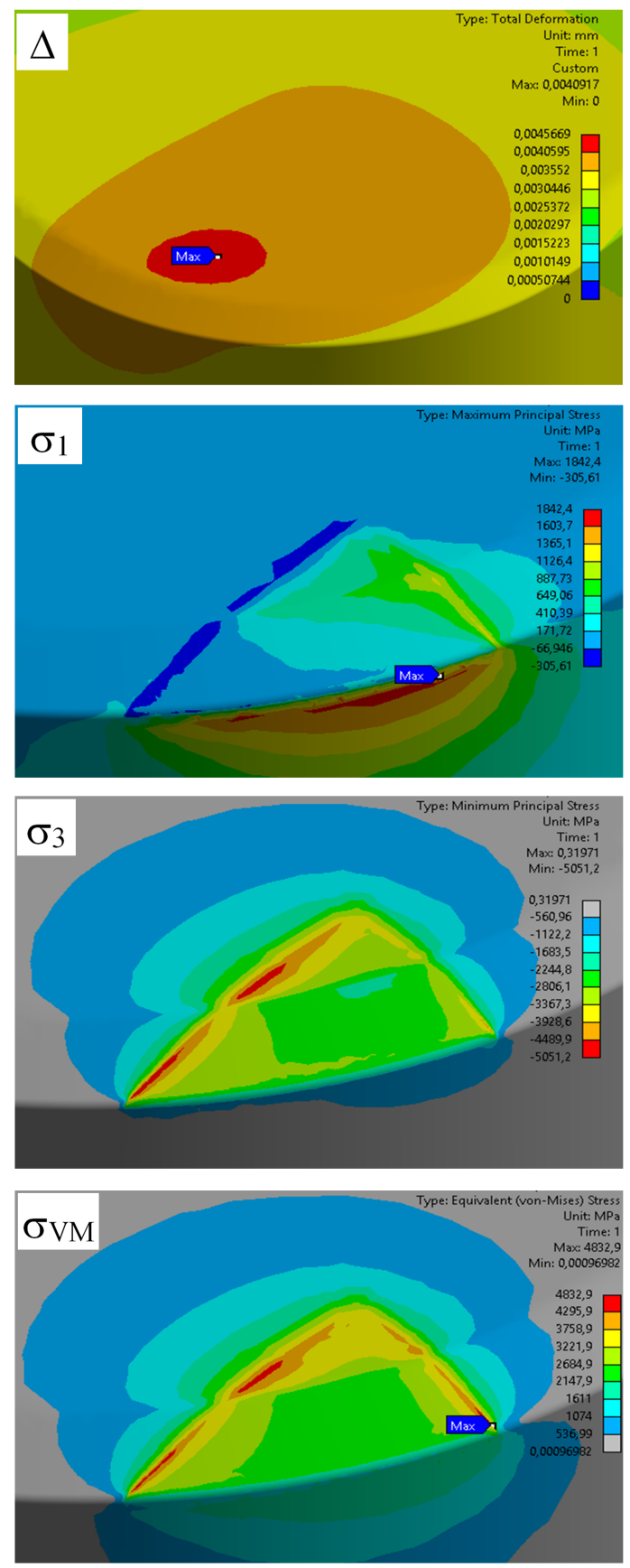

(b)
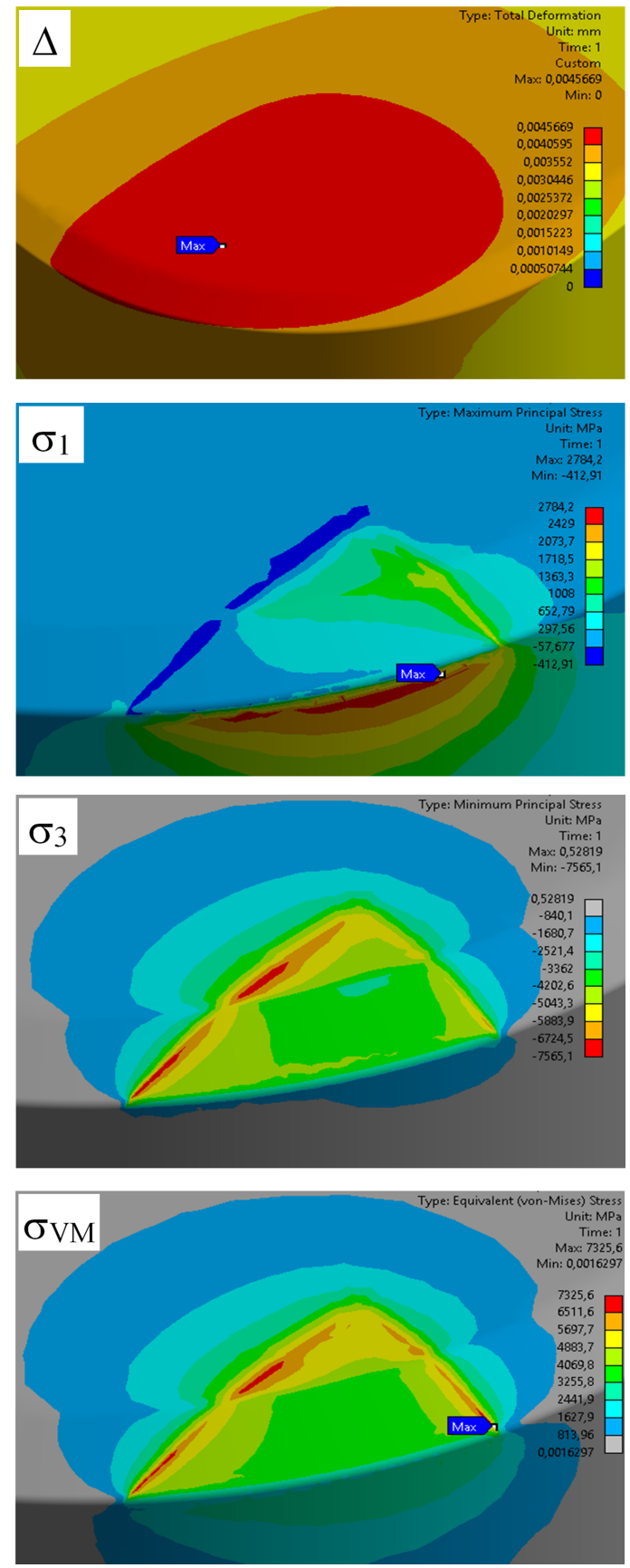

Fig. 4. Distribution of the largest value of $\Delta, \sigma_{1}, \sigma_{3}, \sigma_{\mathrm{VM}}$ for workpiece with hardness of $22 \mathrm{HRc}$ (a) and $52 \operatorname{HRc}(\mathrm{b})$.

For example, the increase in $\sigma_{3}$ was found to be $44.2 \%$ at $V=150 \mathrm{~m} / \mathrm{min}, a=0.2 \mathrm{~mm}$ and $f=0.05 \mathrm{~mm} / \mathrm{rev}$ when increasing the hardness from $22 \mathrm{HRc}$ to $52 \mathrm{HRc}$. However, while increase of $\sigma_{3}$ for hard finishing was $3.8 \%$, the decrease in $\sigma_{3}$ for finish turning of soft material was $6.1 \%$ with the increase of the cutting speed from $150 \mathrm{~m} / \mathrm{min}$ to $250 \mathrm{~m} / \mathrm{min}$ for the same finish turning parameters.

In Fig. 5a, the compression stress on tool rake face in hard turning is lower than that of finish turning of the soft material at $V=350 \mathrm{~m} / \mathrm{min}, a=0.2 \mathrm{~mm}$ and $f=0.35 \mathrm{~mm} / \mathrm{rev}$. In addition, the compression stresses decreased with the increasing tool-chip contact length, depending on depth of cut in all cutting conditions. Namely, the tool-chip contact length increases with increasing the depth of cut and the largest tool-chip contact length decreased the compression stresses.

Figure 5b shows that low tool compression stresses were obtained with increasing the depth of cut from $0.2 \mathrm{~mm}$ to $0.5-0.8 \mathrm{~mm}$. When evaluating the compression 


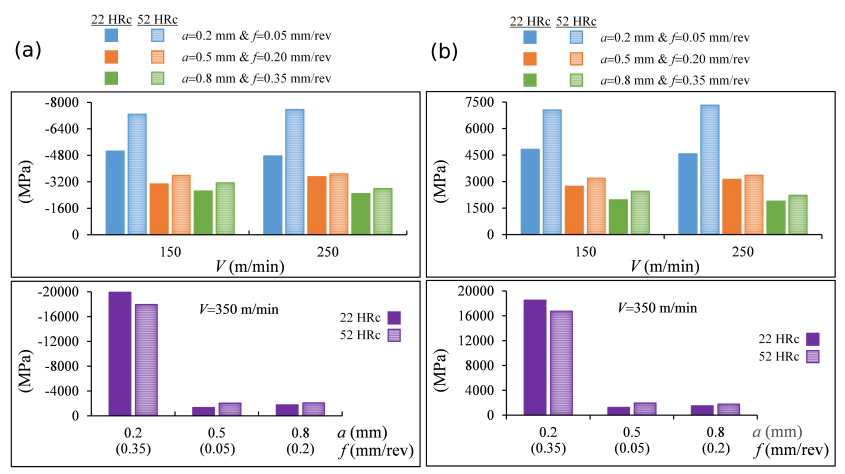

Fig. 5. $\sigma_{3}$ stress (a), and $\sigma_{\mathrm{VM}}$ stress (b) corresponding to various cutting parameters.

stresses, the optimum allowable depth of cut of $0.5 \mathrm{~mm}$ and feed rate of $0.05 \mathrm{~mm} / \mathrm{rev}$ were found considering the minimum compression stress. Figure 5 b shows a similar trend for $\sigma_{\mathrm{VM}}$. The largest $\sigma_{\mathrm{VM}}$ in soft and hard finish turning were, respectively, $18523 \mathrm{MPa}$ and $16762 \mathrm{MPa}$ at $V=350 \mathrm{~m} / \mathrm{min}, a=0.2 \mathrm{~mm}, f=0.35 \mathrm{~mm} / \mathrm{rev}$. The lowest $\sigma_{\mathrm{VM}}$ in soft and hard finish turning were, respectively, 1510.9 and $1957.9 \mathrm{MPa}$ at $V=350 \mathrm{~m} / \mathrm{min}$, $a=0.5 \mathrm{~mm}, f=0.05 \mathrm{~mm} / \mathrm{rev}$.

Figure 4 shows the largest values of $\Delta, \sigma_{1}, \sigma_{3}, \sigma_{\mathrm{VM}}$ for workpiece hardness of $22 \mathrm{HRc}$ and $52 \mathrm{HRc}$. When comparing Fig. 5a and b the total deformation area in hard turning is larger than that in soft material finish turning. It means that even if the total deformation values in hard turning are similar to values in finish turning of soft H13 steel, hard finish turning leads to higher deformation area. The increase in total deformation area is an advantage in metal cutting.

The stress concentration areas of the $\sigma_{1}, \sigma_{3}$ and $\sigma_{\mathrm{VM}}$ are shown in Fig. 4a and b. While $\sigma_{1}$ was $1842.4 \mathrm{MPa}$ and 2784.2 MPa for soft and hard turning under nose radius and cutting edge, compression $\sigma_{3}$ of $-5051.2 \mathrm{MPa}$ and $-7565.1 \mathrm{MPa}$ occurred on the tool rake face. Thus, the stress concentration areas give information about tool failure (wear, fracture etc.).

While the largest compression stresses on tool-chip contact region (rake face) may lead to the crater wear, the maximum tensile stress, occurring under the nose radius and the main cutting edge, can cause the flank and notch wear.

Experimental results [38] support this result by showing that during turning of hard bearing steel with CBN tool, mainly flank wear occurred under the main cutting edge and the crater wear has formed on tool rake face. Huang and Dawson [41] have also investigated crater wear depth in CBN hard turning. In their study, a significant crater wear occurred on rake face at high cutting temperatures and high normal stresses in finish turning. Then in order to model the crater wear one needs high cutting temperatures high normal stresses and high chip velocity on rake face.

In addition, Poulachon et al. [42] experimentally investigated the wear behavior of $\mathrm{CBN}$ tools while turning various hardened steels. They have shown that the crater wear length is a linear function of the tool-chip contact length. In this study the compression stress leading to crater wear on the rake face decreases with increasing tool-chip contact length.

Figure 6 shows a comparison of the $\sigma_{1}, \sigma_{3}$ and $\sigma_{\mathrm{VM}}$ for workpiece with hardness of $22 \mathrm{HRc}$ and $52 \mathrm{HRc}$ at $V=350 \mathrm{~m} / \mathrm{min}, a=0.2 \mathrm{~mm}, f=0.35 \mathrm{~mm} / \mathrm{rev}$. It is an important finding that higher $\Delta, \sigma_{1}, \sigma_{3}$ and $\sigma_{\mathrm{VM}}$ values were obtained while finish turning of soft workpiece material than for hard material. While the maximum total deformation of $0.0061765 \mathrm{~mm}$ occurred on rake face and cutting edge in finishing of soft material, the maximum total deformation of $0.0055734 \mathrm{~mm}$ was obtained in hard turning. Thence, the low tool-chip contact length occurring with $0.2 \mathrm{~mm}$ depth of cut leads to stronger total deformation in turning of soft $\mathrm{H} 13$ with respect to that of hard H13 steel.

This can be attributed to the fact that low depth of cut and high feed rate cause a small chip contact region on rake face. This phenomena together with high compression stress in soft material finishing can complicate the chip flow on rake face. Therefore, a high tool cutting stresses together with high tool total deformations occurred in finish turning of soft material at $V=350 \mathrm{~m} / \mathrm{min}, a=0.2 \mathrm{~mm}, f=0.35 \mathrm{~mm} / \mathrm{rev}$.

Similar trends of $\sigma_{1}, \sigma_{3}$ and $\sigma_{\mathrm{VM}}$, compared to total deformation, were observed in soft material finishing at $V=350 \mathrm{~m} / \mathrm{min}, a=0.2 \mathrm{~mm}, f=0.35 \mathrm{~mm} / \mathrm{rev}$. For instances, $\sigma_{1}=7362.5 \mathrm{MPa}$ in soft material finishing, which is higher than $\sigma_{1}=6612.5 \mathrm{MPa}$ for hard turning.

Similarly, $\sigma_{3}=-19927 \mathrm{MPa}$ in soft material finishing, which is higher than $\sigma_{3}=-17944 \mathrm{MPa}$ for hard turning. Finally, $\sigma_{\mathrm{VM}}=18523 \mathrm{MPa}$ in soft material finishing and $\sigma_{\mathrm{VM}}=16762 \mathrm{MPa}$ for hard turning.

Low workpiece hardness obstructs the chip flow due to low tool-chip contact length/area and smallest total deformation area. Thus, the negative effect of workpiece hardness on total deformation and high tool stresses was obviously observed in this study in finish turning of soft material with $V=350 \mathrm{~m} / \mathrm{min}, a=0.2 \mathrm{~mm}$, $f=0.35 \mathrm{~mm} / \mathrm{rev}$.

\section{Conclusions}

In order to understand the effect of hardness of workpiece material and of cutting parameters on the cutting stresses, the finish turning tests were conducted on the soft (22 HRc) and hard (52 HRc) AISI H13 steel using a low content $\mathrm{CBN}$ insert. The following results were obtained:

- The cutting stresses on low content CBN tool decreased with increasing the tool-chip contact length/area due to increase in the depth of cut.

- Stresses increase with increasing the feed rate. In terms of tool cost, the allowable depth of cut $(0.8 \mathrm{~mm})$ is close to tool radius and the lowest feed rate $(0.05 \mathrm{~mm} / \mathrm{rev})$ must be selected together with high cutting velocity $(350 \mathrm{~m} / \mathrm{min})$ to obtain low tool stresses. 
(a)
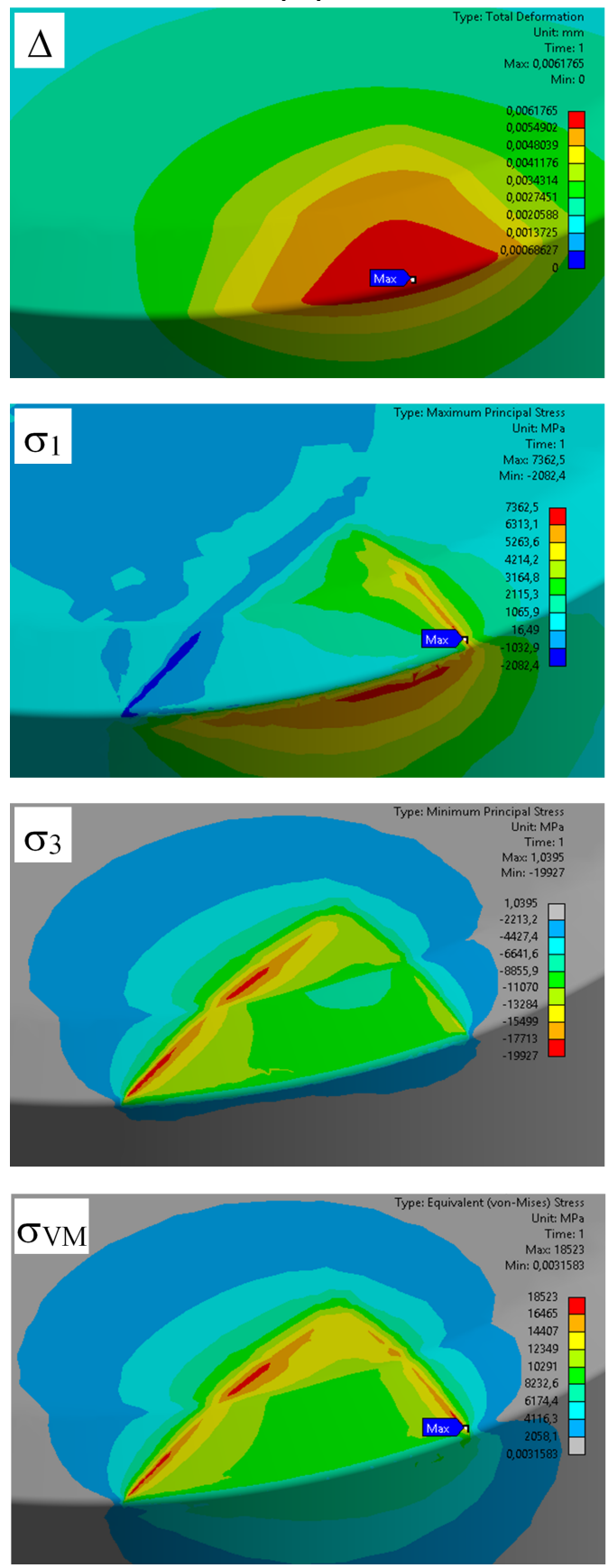

(b)
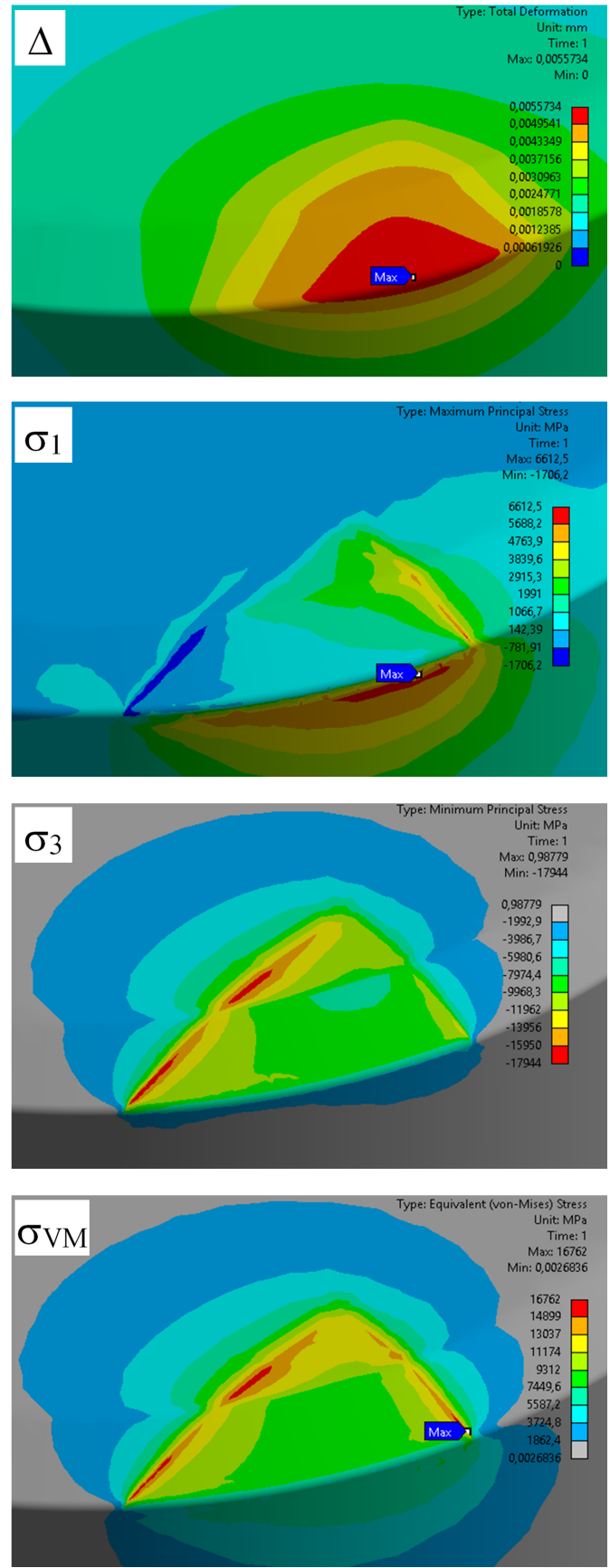

Fig. 6. Distribution of $\Delta, \sigma_{1}, \sigma_{3}, \sigma_{\mathrm{VM}}$ for $V=350 \mathrm{~m} / \mathrm{min}, a=0.2 \mathrm{~mm}, f=0.35 \mathrm{~mm} / \mathrm{rev}$.

- The total deformation increases with increasing the workpiece hardness. Total deformation area in hard turning is larger than that of soft material at finish turning. The total deformation values in finish turning of soft H13 steel are higher than those of hard turning with depth of cut of $0.2 \mathrm{~mm}$, feed rate of $0.35 \mathrm{~mm} / \mathrm{rev}$ and cutting velocity of $350 \mathrm{~m} / \mathrm{min}$.

- The low depth of cut and the high feed rate lead to an increase in tensile stress in $\mathrm{CBN}$ tool at $V=$
$350 \mathrm{~m} / \mathrm{min}$ while turning a soft workpiece material. Generally, the increase of the depth of cut from $0.2 \mathrm{~mm}$ to $0.5-0.8 \mathrm{~mm}$ provides a larger tool-chip contact length/region. Decrease of the feed rate from $0.35 \mathrm{~mm} / \mathrm{rev}$ to $0.05 \mathrm{~mm} / \mathrm{rev}$ makes the chip flow on the tool tip easier. The tensile stresses $\sigma_{1}$ decrease by $11.3 \%$ at increasing the hardness from $22 \mathrm{HRc}$ to $52 \mathrm{HRc}$ in finish turning with depth of cut of $0.2 \mathrm{~mm}$, feed rate of $0.35 \mathrm{~mm} / \mathrm{rev}$ and cutting velocity of $350 \mathrm{~m} / \mathrm{min}$.

- The compression stresses $\sigma_{3}$ decreases with the in- 
crease in depth of cut, providing the large tool-chip contact length/area. The low depth of cut and high feed rate cause a small chip contact region on rake face. For instance, the highest $\sigma_{3}$ was observed at low cutting speed of $350 \mathrm{~m} / \mathrm{min}$, low depth of cut $0.2 \mathrm{~mm}$ and feed rate of $0.35 \mathrm{~mm} / \mathrm{rev}$ in turning of soft (22 HRc) H13 steel. Under same turning condition, $\sigma_{3}$ decreases by $11 \%$ with increasing the hardness from $22 \mathrm{HRc}$ to $52 \mathrm{HRc}$.

- Finally, FEM analyses of tool stresses in CBN tool during sensitive turning shows the possible tool wear mechanisms. The largest compression stresses are focused on tool-chip contact region and may lead the crater wear. The maximum tensile stress occurring under the nose radius and the main cutting edge can cause the flank and notch wear modes when finish turning soft and hard AISI H13 steel. Actually, the CBN insert worn by flank wear combined with the notch wear is in a catastrophic wear mode of the main cutting edge. The craters form on tool rake face in machining tests [38].

\section{References}

[1] H. Aouici, M.A. Yallese, B. Fnides, T. Mabrouki, Mechanica 86, 71 (2010).

[2] S. Dilbag, S.R.A. Venkateswara, Int. J. Adv. Manuf. Technol. 32, 1115 (2007).

[3] Y. Sahin, A.R. Motorcu, Materials and Design 26, 321 (2005).

[4] B.C. Routara, A. Bandyopadhyay, P. Sahoo, Int. J. Adv. Manuf. Tech. 40, 1166 (2009).

[5] I. Lazoglu, K. Buyukhatipoglu, H. Kratz, F. Klocke, Mach. Sci. and Tech. 10, 157 (2006).

[6] T. Özel, Y. Karpat, L. Figgueria, J.P. Davim, J. Mat. Proc. Tech. 189, 192 (2007).

[7] J.G. Lima, R.F. Avila, A.M. Abrao, M. Faustino, J.P. Davim, J. Mat. Proc. Tech. 169, 388 (2005).

[8] S.Y. Luo, Y.S. Liao, Y.Y. Tsai, J. Mat. Proc. Tech. 88, 114 (1999).

[9] P. Koshy, R.C. Dewes, D.K. Aspinwall, J. Mat. Proc. Tech. 127, 266 (2002).

[10] Y.S. Liao, H.M. Lin, Int. J. Mach. Tools and Manuf. 47, 1660 (2007).

[11] Y. Huang, Y.K. Chou, S.Y. Liang, Int. J. Adv. Manuf. Tech. 35, 443 (2007).

[12] Y.K. Chou, C.J. Chris, M.M. Barash, J. Mat. Proc. Tech 124(3), 274 (2002).

[13] L. Qian, S. Lei, R. Chen, ASME Pressure Vessels 202 and Piping Conference, Canada 2006.

[14] H. Aouici, M.A. Yallese, K. Chaoui, T. Mabrouki, J.F. Rigal, Measurement 45(3), 344 (2012).
[15] B. Findes, S. Boutabba, M. Fnides, H. Aouici, M.A. Yallese, Estonian J. of Eng. 19(2), 143 (2013).

[16] Z.N. Farhat, Mat. Sci. and Eng. 361(1-2), 100 (2003).

[17] K. Komvopoulos, S.A. Erpenbeck, J. Eng. Ind. 113(3), 253 (1991).

[18] A. Shih, J. Eng. Ind. 117(1), 84 (1995).

[19] A.Shih, H.T.Y. Yang, Int. J. of Numerical Methods in Eng. 36, 1487 (1993).

[20] J.S. Strenkowski, J.T. Caroll, J. Eng. Ind. 107(4), 349 (1985).

[21] J.S. Strenkowski, G.L. Mitchum, North American Manufac. Res. Conf., Bethlehem 1987, pp. 506-508.

[22] K. Ueda, K. Manabe, CIRP Annals 41(1), 129 (1992).

[23] A. Kurt, U. Şeker, Materials and Design 26(4), 351 (2005).

[24] H. Gürbüz, A. Kurt, İ. Korkut, U. Şeker, Adv. Mat. Res. 23, 191 (2007).

[25] E. Köse, A. Kurt, U. Şeker, J. Mat. Proc. Tech. 196(1-3), 165 (2008).

[26] A. Kurt, Expert Systems with Applications 36(6), 9645 (2009).

[27] H. Gürbüz, A. Kurt, İ. Çiftçi, U. Şeker, Strojniški vestnik - J. of Mech. Eng. 57(2), 91 (2011).

[28] H. Yan, J. Hua, R. Shivpuri, Sci. and Tech. of Adv. Mat. 6(5), 540 (2005).

[29] D. Umbrello, S. Rizzuti, J.C. Outeiro, R. Shivpuri, R.M'Saoubi, J. Mat. Proc. Tech. 199(1-3), 64 (2008).

[30] T. Özel, J. Mat. Proc. Tech. 209(11), 5167 (2009).

[31] Y. Karpat, T. Özel, J. Manuf. Sci. Eng. 130(1), 011001 (2008).

[32] N.N. Zorev, International Research in Production Engineering, ASME, New York 1963, pp. 42-49.

[33] A. Kurt, B. Yalçın, N. Yılmaz, Int. J. Adv. Manuf. Tech. 80, 315 (2015).

[34] A. Toropov, S.L. Ko, Int J. Mach. Tools Manuf. 43(12), 1209 (2003).

[35] S.L. Casto, E.L. Valvo, E. Lucchini, S. Maschio, M. Piacentini, V.F. Ruisi, Wear 225-229, 227 (1999).

[36] Z.C. Lin, S.P. Lo, Int. J. Mech. Sci. 40(7), 663 (1998).

[37] T. Wikgren, M.Sc. Thesis, Luleå University of Technology 2001.

[38] K. Bouacha, M.A. Yallese, T. Mabrouki, J.F. Rigal, Int. J. Refr. Metals Hard Mat. 28(3), 349 (2010).

[39] A. Ibrahim, M.S. Al-Zkeri, Ph.D. Thesis, Graduate School of the Ohio State University 2007.

[40] Y. Matsumoto, Abrasives Magazine 16-19, 31 (1996).

[41] Y. Huang, T.Y. Dawson, Wear 258(9), 1455 (2005).

[42] G. Poulachon, B.P. Bandyopadhya, I.S. Jawahir, S. Pheulpin, E. Seguin, Wear 256(3-4), 302 (2004). 